\title{
¿Merú Levy lexicógrafa? \\ Definiciones y aclaraciones léxicas en el fichero de Cynthia M. Crews
}

El presente trabajo tiene por objetivo abordar la contribución de la informante oral Merú Levy al fichero léxico del judeoespañol de Cynthia Crews y, especialmente, sus definiciones sinonímicas y perifrásticas, con el fin de determinar su autenticidad, establecer -en la medida de lo posible- si son producto de su idiolecto y examinar su fiabilidad como definiciones lexicográficas válidas. Una vez seleccionadas estas explicaciones de entre los miles de papeletas que componen el fichero, el corpus ha quedado formado por más de cuatrocientos ejemplos, que son los que han servido de base para realizar el presente estudio.

Así pues, el artículo consta de: (I) una introducción, donde se presenta el fichero léxico del judeoespañol y las fuentes que lo conforman; (II) una contextualización de la figura de Merú y presentación de su contribución al fichero; (III) una descripción y análisis lingüístico de las aclaraciones léxicas; y (IV) las conclusiones.

Palabras Clave: judeoespañol; informante oral; léxico; lexicografía; diccionarios; estudios sefardíes.

Meru Levy, a Lexicographer? Lexical Glosses and Clarifications in the Cynthia M. CRews's CARD IndeX.- The current research aims to address the contribution of the oral informant Merú Levy to Cynthia Crews's Judeo-Spanish lexical card index, and especially her synonymic and periphrastic definitions, in order to determine their authenticity, to establish -where possible- whether they are a product of her idiolect, and to examine their reliability as valid lexicographic definitions. Once these explanations had been selected from among the thousands of cards that compose the index, the corpus has been

* Este trabajo ha sido realizado dentro del Proyecto de Investigación «Sefarad, siglo XXI (2017-2020): Edición y estudio filológico de textos sefardíes» del Plan Nacional I+D+I (ref. FFI2016-74864-P).

** efmartin@ujaen.es

Copyright: () 2017 CSIC. Este es un artículo de acceso abierto distribuido bajo los términos de una licencia de uso y distribución Creative Commons Attribution (CC-by) España 3.0. 
formed by some more than four hundred examples, which constitute the bases for the present study.

Therefore, this research consists of: (I) an introduction, where we describe the JudeoSpanish lexical card index and the sources that form it; (II) a contextualization of the Merú Levy personality and a presentation of their contributions to the card index; (III) a description and analysis of the lexical explanations; and (IV) the conclusions.

KeYwords: Judeo-Spanish; Oral informant; Vocabulary; Lexicography; Dictionaries; Sephardic Studies.

\section{Introducción: Las fuentes del fichero de Cynthia Crews}

El magno fichero manuscrito de la investigadora británica Cynthia M. Crews contiene múltiple y abundante información para el estudio del léxico judeoespañol. Conformado por aproximadamente 35.000 papele$\operatorname{tas}^{1}$ y recopilado a lo largo de toda una vida de trabajo dedicada a la investigación, este fichero proporciona información fonética, gramatical, etimológica, léxico-semántica y documental, así como recoge sinónimos, variantes lingüísticas y formas equivalentes de los lemas en otras lenguas o dialectos, lo que hace de esta obra una fuente de consulta esencial para todos aquellos interesados en la lengua sefardí2.

Aunque el fichero no constituye en sí un diccionario -ni siquiera presenta homogeneidad en el tratamiento léxico de las papeletas, pues algunas de ellas se desarrollan ampliamente, mientras que en otras solo aparece la categoría gramatical y la definición del lema-, sí fue concebido por la autora como el germen de lo que podría ser un completo diccionario de judeoespañol ${ }^{3}$. Para ello, Crews se encargó de incorporar datos

\footnotetext{
${ }^{1}$ Según los datos proporcionados por Aitor García Moreno, «El proyecto de "Edición del fichero manuscrito de léxico judeoespañol de Cynthia Crews"», en Diacronía de las lenguas iberorrománicas: nuevas aportaciones desde la lingüística de corpus, ed. Andrés ENRIQUe-ARIAS (Madrid: Iberoamericana, 2009) págs. 217-228.

${ }^{2}$ El contenido y naturaleza de este fichero fue descrito ya por Leonor CARRACEDO, «El Judaeo-Spanish Dicionnary de Cynthia Crews», Estudios Sefardíes 2 (1979) págs. 301302. También puede encontrarse una breve reseña sobre el fichero léxico del judeoespañol en Elisabeth BRINE, «A handlist of the Crews Papers in Girton College Library», Estudios Sefardies 2 (1979) págs. 261-275.

${ }^{3}$ La tarea quedó inacabada con el prematuro fallecimiento de Cynthia Crews, aunque su proyecto no cayó en el olvido. El Girton College de la Universidad de Cambridge
} 
de numerosas obras y fuentes de diverso tipo y cronología ${ }^{4}$ (desde los ss. XVI a XX):

1) Testimonios orales recogidos de primera mano por Crews (tanto textos literarios como datos léxicos extraídos de las entrevistas a sus informantes): Merú Levy, Aelión, Abinum, Francés, Sam Levy y su esposa, Nissim Levy, Cohen, London, Assael e, incluso, Michael Molho.

2) Textos originales sefardíes: prensa (v. gr. La pita de noche de šaḅat publicada en el periódico Acción), textos bíblicos y religiosos aljamiados (v. gr. Biblia de Esmirna [1838], Pirqué abot, Me am Lo'ez, Alegría de Purim, Meśa de el Alma, Obligación de los corazones, Treśoro de Israel) y en caracteres latinos (v. gr. Biblia de Ferrara [1553], varias Hagadás).

3) Ediciones de textos: coplas, romances (v. gr. Attias, Bénichou), novelas (v. gr. Retorno a Sefarad), libros de etnografía e historia (v. gr. Usos y costumbres de los sefardies) y libros de proverbios o refranes (v. gr. Besso, Saporta y Beja, Foulché-Delbosc).

4) Estudios clásicos sobre el judeoespañol, como los de Subak, Wagner, Luria, Baruch e, incluso, artículos de la propia Cynthia Crews; así como trabajos bien conocidos de dialectología romance, gramáticas históricas y manuales de historia de la lengua española.

5) Obras lexicográficas: diccionarios y vocabularios de judeoespañol (Cherezli, Benoliel); diccionarios de español (Autoridades, Corominas, varias versiones del Diccionario manual

conservó el fichero hasta 1979, momento en que fue cedido al antiguo Instituto Arias Montano del CSIC, institución esta última que emprendió años más tarde la recuperación e informatización de las papeletas. En la actualidad, el fichero ha sido digitalizado al completo y la edición en formato digital se encuentra en un estado bastante avanzado, como se puede ver en la página web del Grupo de Estudios Sefardíes del CSIC: $<$ http://esefardic.es/dhje_estado $>$. Sobre el proyecto de edición del fichero manuscrito, véase García Moreno, «El proyecto de "Edición”», págs. 217-228.

${ }^{4}$ Crews menciona más de 300 fuentes a lo largo de todas las fichas. No se consigna en el presente trabajo todo el catálogo de obras y autores, pues esta recopilación excedería, sin duda, tanto la extensión como el objetivo principal del estudio. 
de la Academia, el DRAE de 1939, etc.); repertorios dialectales romances, como el Vocabulario andaluz de Alcalá Venceslada o el Vocabulario del bable de occidente de Acevedo y Fernández, por mencionar algunos; y diccionarios de otras lenguas, especialmente, de carácter bilingüe (francés-árabe, francés-turco, turco-italiano, hebreo-inglés...).

De entre las fuentes primarias orales, destaca por su interés, riqueza y abundancia el testimonio ofrecido por Merú Levy; de hecho, esta mujer es con diferencia la informante que más datos aporta al fichero, pues llega a octuplicar las apariciones del siguiente informante con más ejemplos, que en este caso se trata también de una mujer, Estrella Aelión. Los miles de registros que existen de Merú Levy en el fichero no son ni mucho menos casuales, sino que constituyen fiel reflejo de la ayuda que le proporcionó a Crews, de la dedicación que le brindó e, incluso, del interés o agudeza léxica que esta señora podía tener, dadas las respuestas a las continuas preguntas y dudas que la investigadora británica le planteaba en sus entrevistas. Esta informante le sirvió a Cynthia Crews para atestiguar nuevas voces o acepciones de una palabra no localizadas en otras fuentes hasta entonces, así como para confirmar significados y variantes lingüísticas. La misma Crews ${ }^{5}$ dejó constancia escrita de la aportación de Merú Levy a sus investigaciones sobre el judeoespañol, como se puede leer en el siguiente fragmento:

Me complazco en rendir aquí tributo a su paciencia inagotable en responder a todas mis preguntas, que a menudo le parecerían ridículas e interminables. Gracias a estas preguntas he podido añadir referencias a palabras y expresiones de uso corriente en Salónica que no constan en los Textos, basadas en variantes o explicaciones dadas por Merú Levy ${ }^{6}$.

De su relato parece deducirse que las explicaciones que Merú Levy daba eran producto únicamente del afán indagatorio de su interlocutora. Sin embargo, en un reciente trabajo sobre las glosas léxicas, García Moreno $^{7}$ ha demostrado la motivación autónoma de Merú Levy en las

\footnotetext{
${ }^{5}$ Cynthia Crews, «Textos judeo-españoles de Salónica y Sarajevo con comentarios lingüísticos y glosario», Estudios Sefardíes 2 (1979) págs. 91-258.

${ }^{6}$ Crews, «Textos judeo-españoles», pág. 121.

Aitor García Moreno, «Glosas de andar por casa en los cuentos sefardíes tradicionales
} 
aclaraciones ofrecidas por Crews en la transcripción de los relatos de tradición oral recogidos en Salónica en 1935. A lo largo de su análisis, este investigador proporciona argumentos y ejemplos donde Merú parece haber ofrecido espontáneamente muchas de estas improvisadas glosas:

Nuestra impresión es que Merú Levy, ante la general curiosidad lingüística de Crews en sus reuniones, iba de manera más o menos autónoma aclarando el valor de determinadas voces o expresiones que en su opinión podrían resultar interesantes o difíciles para la encuestadora, y tales son las que aparecen incorporadas como glosas en los textos en prosa de nuestro original. [...] El resto de las aclaraciones directamente inducidas por la investigadora británica con sus cuestiones -ya interrumpiera o no a su informante para conseguirlas-, habrían pasado a engrosar sus apuntes (y posterior fichero léxico), pero quedaron fuera de los textos, tal vez por no haber partido inicialmente de la Sra. Levy ${ }^{8}$.

No ocurriría lo mismo en el caso del fichero, en opinión de este autor, pues a él habrían pasado los ejemplos inquiridos por Crews. No está claro entonces el grado de iniciativa e implicación de esta informante en las definiciones y explicaciones léxicas que ofrece Crews en su fichero, dado que tampoco la investigadora justifica su manera de citar la información en las papeletas -que es bastante heterogénea, como se verá más adelante- ni su modo de proceder en el tratamiento de las fuentes orales. No obstante, lo que sí queda de manifiesto es que, ya fuese por las preguntas de la investigadora, ya por iniciativa de la propia Merú Levy, esta informante fue la fuente de múltiples explicaciones léxicas que llegaron a trasladarse al fichero del judeoespañol.

Teniendo en cuenta, por tanto, la riqueza del testimonio y las aportaciones de Merú Levy al contenido del mencionado fichero, nos pareció de obligado interés realizar un análisis de sus contribuciones, especialmente de las definiciones tanto de tipo sinonímico como perifrástico y explicativo, con el objetivo de determinar su autenticidad y originalidad, establecer, en la medida de lo posible, si son producto de su idiolecto y examinar su fiabilidad como definiciones lexicográficas válidas.

recogidos por Cynthia Crews en Salónica a principios del siglo XX», Ladinar VII-VIII (2014) págs. 95-112.

${ }^{8}$ García Moreno, «Glosas de andar por casa», pág. 105. 
Para ello, se hizo una selección de estas ampliaciones léxicas de entre todos los ejemplos de Merú Levy que aparecen en el fichero, lo que arrojó un corpus formado por 445 muestras, que son las que han servido de base para el presente estudio y las que procedemos a describir y analizar a continuación.

\section{Merú Levy y su presencia en el fichero de Cynthia Crews}

Antes de pasar a exponer el tipo de información léxica que proporciona la Sra. Merú Levy y cómo se presentan las aclaraciones de lema en el fichero, conviene explicar quién era realmente esta informante para poder calibrar con mayor juicio su testimonio.

\subsection{El interés por Merú Levy como informante}

Según cuenta Crews ${ }^{9}$, Merú Levy tenía 55 años en 1935 y era natural de Salónica, hija y nieta de tesalonicenses, analfabeta y ciega «desde la edad de seis años a consecuencia de la viruela», hecho que impidió que aprendiera a leer. Su analfabetismo indicaba que todo el repertorio literario que Merú Levy conocía (cuentos, romances y canciones) solo podía haberle llegado por vía oral y que solamente de este modo pudiera a su vez transmitirlo; de hecho, fue así cómo se lo proporcionó a Crews. Mientras Merú Levy iba contando, recitando y explicando lo que recordaba, la investigadora iba a su vez transcribiendo, a la luz de un quinqué, sus palabras.

Otra característica importante de Merú Levy era que no poseía amplios conocimientos de otras lenguas, lo que la convertía en una perfecta informante y en ejemplo representativo de la norma de Salónica. Merú Levy tenía «ligeras nociones de turco y de griego y estaba familiarizada con las expresiones hebreas de uso sinagogal» ${ }^{10}$, pero de inglés y francés solo conocía unas pocas palabras, competencias estas muy limitadas que, en opinión de Crews, no podían influir en su judeoespañol.

\footnotetext{
${ }^{9}$ CRews, «Textos judeo-españoles», pág. 121.

${ }^{10}$ CRews, «Textos judeo-españoles», pág. 121.
} 


\subsection{La representación en el fichero de las aportaciones de Merú Levy}

Las citas que hay de Merú Levy en el fichero son de distinta naturaleza y no todas ellas constituyen definiciones y aclaraciones léxicas. La información que proporciona sirve para atestiguar: a) lemas, b) lexías complejas, c) variantes, d) ejemplos, e) sinónimos y expresiones equivalentes, f) acepciones y, por último, g) el género gramatical de ciertos adjetivos y sustantivos. Aunque el interés de este trabajo se centra en analizar las aclaraciones léxicas de tipo sinonímico y perifrástico, es necesario conocer previamente cómo se presentan en el fichero de Cynthia Crews todas las aportaciones de esta informante.

Las referencias a Merú Levy (o ML, abreviatura con la que se representa en las papeletas) se encuentran, por lo general, en la parte central del cuerpo de la ficha, junto con el resto de fuentes orales, las documentaciones en textos escritos, los estudios que mencionan la palabra -si los hay- y, ya en la parte inferior, la información de tipo etimológico, tal y como se muestra en la imagen 1, perteneciente a la palabra «mađero».

No obstante, la mención ML también puede situarse en la esquina superior derecha de la papeleta, acompañada de la marca geográfica Sal. (Salónica), e incluso, aunque esto sea menos habitual, estar presente tanto

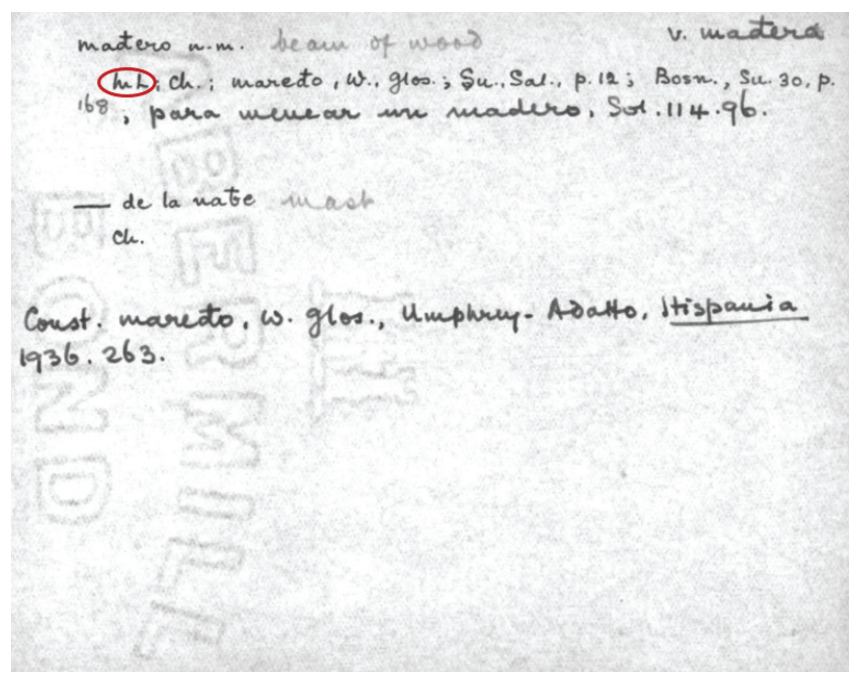

Imagen 1. Ficha del lema «mađero» 
en el cuerpo interior como en el vértice de la hoja, como se puede apreciar en la ficha del lema «tálamo» (imagen 2). Merú Levy es curiosamente la única fuente informativa que tiene esta llamada en la parte superior, escrita quizá por motivos prácticos para facilitar la búsqueda y localización manual de los términos tesalonicenses en el fichero.

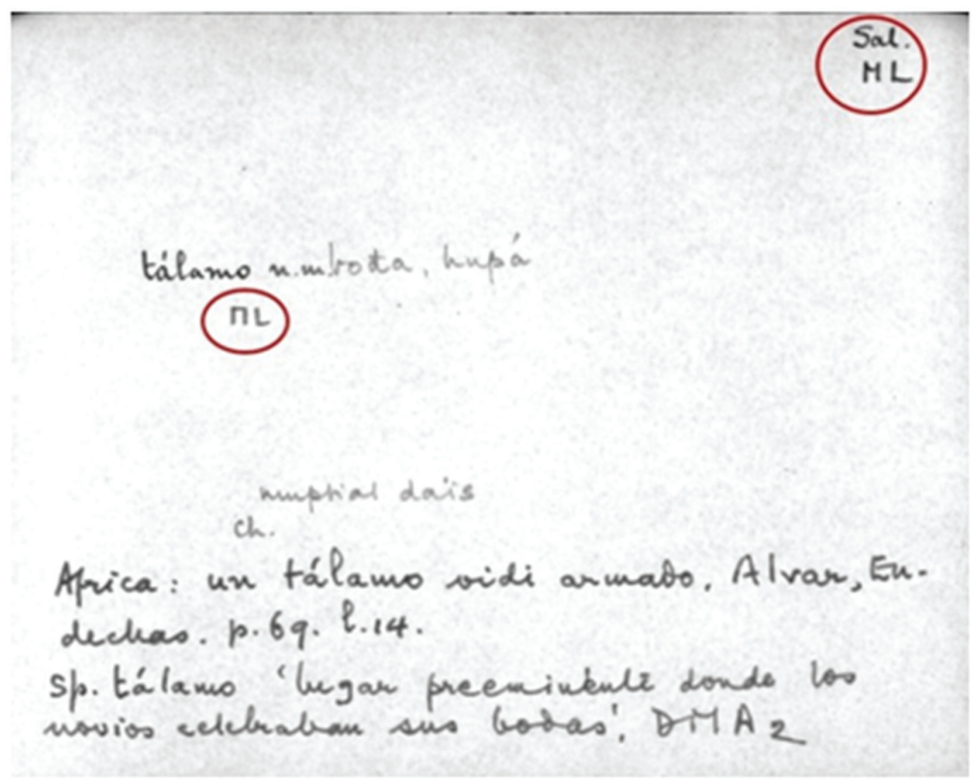

Imagen 2. Ficha del lema «tálamo»

La mayor parte de las citas que hay de Merú Levy en las fichas son tan escuetas como las que se acaban de ver en las imágenes 1 y 2 , menciones que sirven meramente para atestiguar el lema, pero no amplían información léxica de ningún tipo. Semejante concisión se debe, por un lado, a que se trata de información oral de la que no es posible añadir los datos de localización -como sí aparece de los materiales escritos-y, por otra parte, al hecho de que tanto el lema de entrada como la definición coinciden con lo mencionado por la informante o, incluso, sean aportación suya y, en consecuencia, no sea necesario volver a notarlos en la ficha.

En lo que respecta ya a las citas con aclaraciones léxicas, hay que hacer constar, en primer lugar, que los testimonios de Merú Levy aparecen reproducidos en un sistema de transcripción fonética bastante sencillo, lo 
que indica que fueron puestos por escrito directamente de su informante oral. Así lo explica la misma Crews en su introducción a la edición de los Textos judeo-españoles de Salónica y Sarajevo:

Como mi estancia en Salónica y Sarajevo no fue de larga duración, procuré usar en mi reproducción manuscrita de lo que oía (pues no disponía de aparatos registradores) el alfabeto fonético más sencillo posible, reduciendo al mínimo el número de signos diacríticos y prescindiendo de indicar el timbre exacto de los sonidos vocálicos ${ }^{11}$.

En segundo lugar, hay que advertir también que estas definiciones no muestran sistematicidad y uniformidad en los criterios de presentación y edición, sino que varían en la simbología y los recursos empleados para organizarlas. Tal heterogeneidad en la microestructura pone claramente de manifiesto el carácter de obra en curso, así como la naturaleza provisional y la poca planificación de los criterios de presentación escrita.

Uno de los mecanismos gráficos más utilizados en estas ampliaciones es el uso del símbolo $=$. Se suele emplear en las definiciones sinonímicas o sintéticas ${ }^{12}$; es decir, aquellas en las que Crews define el lema de entrada con un término equivalente. La palabra introducida mediante el símbolo igual puede aparecer tanto acompañada del lema (1a) como no presentarlo (1b). Tales equivalencias sinonímicas no son exclusivas de dos términos que se ponen en relación, sino que pueden estar formadas por tres o cuatro elementos (definiciones sinonímicas acumulativas), encadenados mediante este símbolo de igualdad (1c) o unidos entre ellos por comas (1d). Este signo también se puede utilizar para las definiciones perifrásticas, como ocurre con el ejemplo de la voz trapán (1e), que es definido como 'cuchillo para cortar el trigo'.

\section{1. a) Sal. surtír = kagár, $\mathrm{ML}^{13}$}

\footnotetext{
${ }^{11}$ CREWS, «Textos judeo-españoles», pág. 100.

12 José Álvaro PoRto Dapena, Manual de técnica lexicográfica (Madrid: Arco Libros, 2002) págs. 285 y siguientes.

${ }^{13}$ Todos los ejemplos que se incluyen en el presente trabajo se citan en el sistema de transcripción fonética simplificado utilizado por Cynthia Crews en el fichero (vid. CREws, «Textos judeo-españoles», pág. 100) y con los mismos mecanismos de representación gráfica que la investigadora británica usó para redactarlos. En lo que respecta a este último aspecto, se ha intentado ser lo más fiel posible a la ficha lexicográfica original y al
} 
b) $[$ sistrano, -a $]=$ fulano, -a, ML

c) afilar = labrar = kađrar

d) bandiđo = čakal, ombre negro, ML

e) Sal. trapã = kučiyo para kortar el trigo ML

En segundo lugar, Crews se sirve de otro recurso tipográfico, las comillas (simples o dobles), que suele ser mucho más común en las definiciones perifrásticas, aunque no es exclusivo de ellas, como se acaba de ver en el último ejemplo. En el caso de aguźar (2), se puede observar cómo se estructura la definición utilizando estos signos dobles: primero aparece la marca geográfica (Sal.), después se repite el lema de entrada y, a continuación, entre comillas, se incorpora el significado de la palabra en judeoespañol, seguido de las iniciales ML:

\section{Sal. aguzar 'ezmolar el kučiyo', ML}

A veces, lo incorporado entre comillas es una acotación semántica en inglés que sirve para interpretar el sentido de una palabra. Este tipo de precisiones son, sin duda, obra de Cynthia Crews, pues hay que recordar que Merú Levy no dominaba la lengua inglesa. Mediante esta limitación del significado, Crews intenta aclarar la polisemia y cualquier ambigüedad que pudiera surgir o presentársele en el futuro al consultar el fichero. Así sucede con la palabra tachón (3), que es definida como 'mancha', voz que puede tener diferentes acepciones, tal y como se comprueba al consultar su ficha lexicográfica: por un lado, significa 'mancha de la ropa',

modo -no uniforme- en que Crews registra las citas de Merú Levy. Así, se emplean las comas, los puntos y el signo igual tal y como se recogen en las fichas; y solo se anota la abreviatura Sal. (marcada en cursiva) y las iniciales ML cuando estos elementos aparecen junto a la definición de la informante, pero no cuando se sitúan en la esquina superior de la papeleta -de ahí que ambas marcas no estén presentes en todos los ejemplos de este trabajo, como se podrá ver en el ejemplo 1c, a continuación. No obstante, con el fin de facilitar su lectura e identificación, nos hemos servido de ciertos recursos tipográficos, como son los corchetes, la negrita y la cursiva: entre corchetes se repone el lema al que remite la cita de Merú Levy cuando este no aparece en la definición; en negrita se resalta dicho lema para diferenciarlo del resto de elementos; y, por último, en cursiva se destaca la definición que Crews proporciona en inglés. 
pero también puede ser 'peca' (ambos significados conocidos por Merú Levy) y, en sentido figurado, 'deshonra'.

3. Sal. tačón = manča 'spot on clothes', ML

Dichas matizaciones de significado pueden estar presentes tanto en los lemas de entrada como en las equivalencias, según se ve en los casos 4a y 4b:

4. a) embarasađo, -a 'busy; tiene fečos', ML

b) Salon. safumeryo 'sort of incense put under child's bed when it's afraid' = pasas, ensensyo, ML

Ambos caracteres gráficos (símbolo de igual y comillas) se utilizan indistintamente sin que exista un criterio que justifique el uso de uno u otro recurso de manera diferenciada. En ocasiones, incluso, pueden usarse en combinación, sobre todo cuando se incluyen aclaraciones en inglés, según se ha podido ver en los ejemplos 3 y $4 \mathrm{~b}$.

\section{Descripción y análisis de las definiciones de Merú Levy}

Las definiciones proporcionadas por Merú Levy en el corpus se refieren, como es esperable, a palabras léxicas de significado conceptual: principalmente sustantivos (61\%), seguidos de verbos o locuciones verbales (27\%), adjetivos o locuciones adjetivas (9\%) y, en escasa medida, adverbios o locuciones adverbiales $(2 \%)$. No obstante, aparecen explicadas algunas palabras gramaticales $(<1 \%)$, que funcionan como deducciones de la propia Crews con fines aclaratorios: una interjección, una contracción y un par de pronombres. Estos últimos son en realidad dos formas de tratamiento (5a y 5b), cuya definición sinonímica se debe, a buen seguro, a una descripción del uso de Merú Levy por interés práctico de Crews, ya que estas formas podían presentar per se valores sociolingüísticos o dialectales diferentes en aquella época ${ }^{14}$.

\footnotetext{
${ }^{14}$ La historia de las formas de tratamiento en judeoespañol merece un estudio detenido, pues presenta, sin duda, una evolución muy diferente de la del español de España y de
} 
5. a) $[$ bos $]=$ usté, $\mathrm{ML}$

b) Sal. usté ‘bos', ML

Como se puede comprobar, el corpus está formado fundamentalmente por sustantivos, nociones que permiten aproximarse a los objetos, las personas y el mundo natural, que sirven para designar realidades conocidas por la informante y que presentan una marcada intención aclaratoria. Después de todo, Merú Levy solo podía definir aquello que no le era ajeno, hecho que no implica, claro está, que esas aclaraciones hubieran partido siempre de su propia voluntad, sino que podían ser resultado de las preguntas que la investigadora le iba planteando al hilo de su conversación o de la transcripción de los textos.

Gran parte de la selección de la nómina léxica definida por Merú Levy parece haber venido motivada por Cynthia Crews, de ahí la presencia en el corpus de esas palabras gramaticales, que Merú Levy, motu proprio, no habría glosado, así como de la existencia de ciertos antropónimos (6a y 6b) y topónimos (7a y 7b) sobre los que le habría preguntado. La definición que Merú Levy ofrece de estos nombres propios es muy rudimentaria, especialmente en el caso de los topónimos, que suelen definirse como 'sivdá', a pesar de que algunos sean en realidad continentes o países. El término ciudad funciona, sin duda, como hiperónimo, en lugar del tecnicismo lingüístico:

6. a) $[$ Diamante $]=$ nombre de mužer, $M L$

b) Alfonso nombre đe ombre

7. a) $[$ Marsiya $]=$ sivdá, $M L$

b) Italya sivdá

Véase, por ejemplo, el caso de Italia (7b), palabra que aparece mencionada en los textos de Salónica, concretamente en el 20 (Dicen que te

América. Por ejemplo, Kalmi Baruch (en «El judeo-español de Bosnia», Revista de Filología Española 17 [1930] págs. 113-154: 118) afirmó a principios del siglo XX que en el judeoespañol de Bosnia la forma vos (con valor respetuoso) seguía empleándose, pero ya en raras ocasiones. 
vas a Italia $)^{15}$, lo que demuestra que buena parte de las definiciones parten de las palabras de estos textos y a su vez el fichero enriquecía también el glosario que los acompañaba.

En lo que respecta a la redacción de las definiciones, es notable el interés de Crews por procurar recopilar toda la información que Merú Levy le proporcionaba. No en vano, las equivalencias sinonímicas que le ofrecía le sirven a Crews para remitir a otras palabras del fichero y crear verdaderos campos semánticos. No obstante, es cierto que en algunas ocasiones Crews duda de la veracidad de lo expresado por su informante o de su propia capacidad de interpretación, como se ve en los ejemplos de 8. En 8a Crews cuestiona si la forma calamia existe realmente o se trata de una errónea interpretación de la palabra cabaña, que es lo más probable, ya que esta palabra no aparece en otras fuentes ni tampoco se ha localizado en el diccionario de Nehama ${ }^{16}$. En el ejemplo 8 b la duda se encuentra en el significado que proporciona Merú para la voz masero, que no coincide con el que aportan otras fuentes, pues mientras que para ella significa 'artesa', el resto la definen como 'mantel', significado que también aparece recogido en el diccionario de Nehama. Ambos casos son interesantes para comprobar que el fichero no era un mero «cajón de sastre», sino que también conllevaba un proceso de reelaboración de los apuntes manuscritos previos y de revisión.

8. a) Salon. kalámina = sukó, feast of tabernacles (a mishearing by $M L$ or by me?)

b) Salon. masero đe pan 'kneading-trough' ML Is this an error?

Por otra parte, estos cuestionamientos también revelan la preocupación de Crews por no desdeñar ninguna información de su interlocutora. Lo primero debía ser anotarla, después, ya se planteaba y analizaba si era o no correcta y en el caso de que no lo fuese, sería tachada y corregida. Parece plausible pensar entonces que las definiciones y explicaciones léxicas del fichero existentes eran el producto de lo que Merú realmen-

\footnotetext{
${ }^{15}$ Crews, «Textos judeo-españoles», pág. 159.

${ }^{16}$ Joseph Nehama, Dictionnaire du Judéo-Espagnol (Madrid: CSIC, 1977).
} 
te había dicho. Prueba de ello es el hecho de que, en primer lugar, las palabras del definiendum y del definiens son en su mayor parte de base hispánica (v. gr. cośa, perdonar, quemar), turca (v. gr. asquier 'soldado', charši 'mercado', biliŷicos 'bretes') o hebrea (v. gr. malah, hayá) y aunque se detectan algunos helenismos (v. gr. ahti 'preocupación, desvelo'), lusismos (v. gr. caśal, choca) e italianismos (v. gr. escarso), estos son de carácter común, hecho que encaja, en líneas generales, con los conocimientos lingüísticos que tenía Merú Levy ${ }^{17}$.

En segundo lugar, sus definiciones están formuladas en un lenguaje coloquial, tal y como se puede ver en el uso reiterado de ciertas palabras en las definiciones, por ejemplo, los adjetivos bueno (9a y 9b) y grande (9c, 9d y 9e), así como el empleo de verbos polisémicos (nótese el uso recurrente del verbo meter ('poner') en los ejemplos 9f, 9g y 9h) y la presencia de significados algo simples y no demasiado ortodoxos (9i):

9. a) [albisyas] $\mathrm{ML}=$ haber [tc. haber 'noticia'] bweno

b) áspero = fruto kon wezmo bweno

c) [katinela] atwuendo grande, ML

d) [ğeneral] un grande đel reynađo, ML

e) ǧentío muča ğente grande

f) embotar meter en la bota

g) [afinkar] = meter una koza, ML

h) [banka] onde meten las parás

i) [konfesar] = kitar unas palaநras de su meoyo, ML

No obstante, a pesar de esta falta de preparación filológica, Merú Levy consiguió ofrecer de manera inconsciente una amplia tipología de definiciones léxicas; así, aparecen en las fichas definiciones por sinonimia, perifrásticas, morfosemánticas, mixtas, enciclopédicas y de uso. A estos tipos se pueden añadir algunos ejemplos en los que más que definiciones se puede hablar de explicaciones a partir de asociaciones de ideas, que muestran el vocabulario disponible de la Sra. Merú Levy.

\footnotetext{
${ }^{17}$ García Moreno («Glosas de andar por casa», pág. 106) encuentra este mismo resultado al analizar las glosas de los textos en prosa.
} 
De entre todos estos tipos de texto definitorio representados, el que utiliza con mayor frecuencia es el de la definición sinonímica. Hay que tener en cuenta que este tipo es menos preciso que el de la definición perifrástica, ya que es difícil encontrar voces que funcionen como sinónimas en todos los contextos de uso de una palabra, aunque también es cierto que es el constituyente más inmediato y rápido de formular.

Un ejemplo de lo problemático que resulta definir mediante sinónimos se encuentra en la voz «acuchillar» (10), que es definida como 'degollar', pero ambas palabras no tienen el mismo significado (acuchillar quiere decir 'herir, cortar o matar con el cuchillo', mientras degollar es un término más específico y significa directamente 'cortar la garganta') y, por ende, no son conmutables, requisito imprescindible en este tipo de definiciones en un verdadero diccionario.

10. akučiyar = degoyar 'slash, $c u t '$

Tampoco constituye una definición lexicográfica válida aquella cuyo definidor es un hiperónimo, como ocurre en los ejemplos de 11, pues no se cumple el principio de equivalencia semántica entre las dos unidades léxicas:
11. a) [bagaláư ] = peše, $M L$
b) [dukađo] moneđa, ML
c) [falkón] = abe, $\mathrm{ML}$
d) Salon. lilá "flor", Merú Levi ${ }^{18}$

Para que funcionen como verdaderos sinónimos, ambos términos tienen que poder ser intercambiables en todos los contextos y deben presentar además la misma categoría gramatical, hecho este último que a veces no se da en las equivalencias, como se puede comprobar en los ejemplos a continuación:

\footnotetext{
${ }^{18}$ Crews desarrolla en este caso el nombre de su informante y lo escribe fonéticamente, como aparece también en su transcripción mecanografiada de los relatos de tradición oral recogidos en Salónica en 1935 ( $c f$. García MoReno, «Glosas de andar por casa», pág. 98).
} 
12. a) [yugo] 'speed, haste' = prisurozo

b) goisyo = ğuzgar

Es frecuente que se incurra en este tipo de definiciones en errores de circularidad, es decir, en equivalencias sinonímicas en las que una palabra A es definida con B que a su vez es definida de nuevo con A, sin que exista ninguna otra explicación que esclarezca el significado de ambas. Dicha autosuficiencia tiene lugar en los ejemplos de 13 a 14, donde sanar remite a amahar, y viceversa; talún ('hilera', $c f$. tc. talim) a rango y este otra vez a talún.

13. a) Salon. sanar 'amahar'. ML

b) [amahar] sanar. ML

14. a) rrango $=$ talũ 'single file'

b) $[$ talũ $]=$ rrango, "single file", ML

Con carácter explicativo y desambiguador, a veces se añade un ejemplo de uso que acompaña al sinónimo de la definición, como ocurre con el verbo acechar (15a) y el sustantivo fanega (15b):

15. a) asežar = mirar; asežar por loz burakos

b) Salon. fanega = kutla; fanega đe sebađa, đe trigo, ML

Otro problema de este tipo de definiciones tiene lugar cuando el definiens es una palabra polisémica, como ocurría en el ejemplo 3, donde mancha solo podía funcionar como verdadero sinónimo de tachón en algunas de sus acepciones y para evitar la definición imprecisa se incluye la matización en inglés. Lo mismo sucede en el ejemplo (16), donde costumbre es definida por 'usanza, camisa', todas ellas palabras polisémicas, por lo que hasta que no se añade la acotación 'menstruation' no es claramente identificable el significado que se pretende explicar.

16. Salon . kostumbre $=$ uzansa $=$ kamiza 'menstruation', ML 
En lo que respecta a las definiciones perifrásticas, por lo general suelen ser bastante concisas, aunque se configuran mejor que las definiciones sinonímicas, ya que están formadas por un elemento hiperónimo o un archilexema de la misma categoría gramatical que el vocablo definido y un sintagma que lo concreta, como ocurre con los ejemplos de 19.

17. a) $[$ apasentar] $=$ traer a komer a laz obežas, ML

b) akobrar = arrekavdar parás

c) Salon. maya 'bistiđo đe azero', ML

Otro tipo de definición parecida es la morfosemántica, que se caracteriza por una correspondencia total o parcial del lema definido y de su definición, sobre todo cuando la entrada se trata de una palabra derivada o un verbo protético formado a partir de un sustantivo, tal y como se puede ver en los ejemplos a continuación:

18. a) arregađor $=$ arrega agwa

b) Salon. sobrebiađo, -a 'tiene sobrebio', ML

c) embarkar subir al barco

d) embotar meter en la bota

e) embragađo, $-\mathbf{- a}=$ se mityó bragas

f) [enfornar] meter al forno, ML

Menos frecuentes aún son las definiciones mixtas, las construidas por un sinónimo y una oración explicativa, como la del ejemplo 19.

19. [sobrebiarse] eñerbarse; s'asoflamó đe kayentura, ML

Por otra parte, se localizan las definiciones enciclopédicas, que son mucho más extensas que las vistas hasta el momento y de las que se encuentran bastantes muestras en el corpus. Algunos ejemplos interesantes son los siguientes: 
20. a) la asíbar: se mete en možo kon rakí i se unta los pisones; ez amargo i no bebe la kriatura, ML

b) [ágila] = abe đe los syelos, abre laz alas i sube enriba, ML

c) Sal. asafrán 'espésyo ke se bénde al ĉarší', ML

d) buske = lugarez eskondiđos onde ay arbolerías, onde lađrones s'eskonden

e) [futanela] = burako en el braso para kitar sangre i đempwés meten un garbanso i una foža bedre i se lo kuran kađa đía, ML

Próximas a este tipo de definiciones se sitúan aquellas que contienen notas de uso, como las expresadas en 21 , ambas introducidas por «se dice»:

21. a) [ambos, -as] loz dos: se đize kuando se melda la ley, ML

b) ečar biná "se dize kwando se fragwa un konák", ML

En último lugar se hallan aquellos ejemplos que no constituyen una definición propiamente dicha, sino que más bien parece tratarse de asociaciones explicativas en las que se ofrece una cualidad descriptiva del objeto real que se está definiendo. Estos casos revelan que se trata claramente de las respuestas que Merú Levy ofrecía a las preguntas que Crews le iba planteando. Solo así se puede entender la explicación 'es verde' (22a) como definición para mošca de caballo y 'con esto se hace cena' (22b) en el caso de engenara ('alcachofa').

22. a) [moška de kabayo] ez beđre, ML

b) enğenara kon esto se faze sena, fruit covered with leaves

Así pues, teniendo en cuenta el análisis visto hasta el momento, es posible afirmar que los lemas definidos están en gran medida determinados por Crews, aunque la definición aportada sea el producto de lo dicho por Merú Levy, dada la escueta elaboración de las definiciones y el lenguaje empleado en las mismas. 


\section{Conclusiones}

A lo largo de la descripción y el análisis de la aportación de Merú Levy al fichero del judeoespañol de Cynthia Crews ha quedado patente que el testimonio que proporcionó esta informante fue de gran riqueza y un valor lingüístico innegable; pero, a pesar de la agudeza y capacidad explicativa que esta mujer pudiera llegar a tener, no era lexicógrafa ni lingüista, y sus definiciones espontáneas y coloquiales no pueden ser utilizadas directamente como definiciones lexicográficas válidas, como se ha podido comprobar en la mayor parte de los casos. Para que puedan funcionar como definiciones en un diccionario es necesario un proceso de planificación y revisión previa, que evite los errores y cumpla con los principios básicos de una buena definición lexicográfica.

Por otra parte, aunque el testimonio de Merú Levy sea bastante fiel a la realidad lingüística en la que se encuentra inserto, necesita de otras fuentes con las que contrastar los datos y resolver también las ambigüedades o malentendidos que hayan podido surgir en el intercambio comunicativo o en el proceso posterior de transcripción y puesta en limpio de los datos. Es incuestionable el valor de testimonios orales de este tipo como punto de partida de cualquier repertorio léxico, pero también es indudable la necesidad de contar con un amplio corpus textual en el que queden inventariadas todas las formas y significados constatados, pues solo así se podrán establecer las verdaderas relaciones semánticas entre las palabras judeoespañolas, fijar sus matices y definir con precisión y cuidado cada una de las acepciones correspondientes.

Recibido: $14 / 09 / 2017$

Aceptado: 31/10/2017 